\title{
ВЛИЯНИЕ ПРИРОДНОГО ПИГМЕНТА ЖИМОЛОСТИ НА ОПТИЧЕСКИЕ СВОЙСТВА НАНОЧАСТИЦ Аи И Аu/Ag, СТАБИЛИЗИРОВАННЫХ В ОБРАТНО МИЦЕЛЛЯРНЫХ РАСТВОРАХ
}

\author{
(C) 2018 К. Ф. Чернышова, А. А. Ревина \\ Институт физической химии и электрохимии им. А.Н. Фрумкина РАН, \\ Ленинский проспект, 31, корп. 4, 119071 Москва, Россия \\ e-mail: karish@list.ru
}

Поступила в редакцию 27.03.2018

\begin{abstract}
Аннотация. В настоящей работе представлены результаты исследования оптических свойств наночастиц серебра, золота и биметаллических наночастиц золота-серебра, полученных в обратно мицеллярных растворах при использовании реакции химического восстановления ионов $\mathrm{Me}^{\mathrm{n}+}$ в присутствии молекулярного кислорода и восстановителя из класса флавоноидов - кверцетина. Методом UV-VIS спектрофотометрии определены кинетические характеристики процессов формирования наночатиц $\mathrm{Au}$, биметаллических наночастиц $\mathrm{Au} / \mathrm{Ag}$ и их стабильность в зависимости от времени хранения. Особое внимание было уделено изменению характеристик полос оптического поглощения обратно мицеллярных растворов наночастиц $\mathrm{Au}$ при введении в раствор спиртового экстракта природных пигментов из жимолости Lonicera caerulea. Дополнительная информация по влиянию присутствия пигментов жимолости на оптические свойства обратно мицеллярных растворов наночастиц Аи была получена при изучении спектров люминесценции этих растворов.
\end{abstract}

Ключевые слова: наночастицы металлов, биметаллы, обратные мицеллы, спектры оптического поглощения, спектры люминесценции, степень гидратации, природные пигменты.

DOI: https://doi.org/10.17308/kcmf.2018.20/521

\section{ВВЕДЕНИЕ}

Наночастицы (НЧ) благородных металлов золота и серебра привлекают большое внимание благодаря своим уникальным свойствам и функциональной активностью $[1,2]$. Особенно это относится к биметаллическим композитным НЧ, в которых проявляются особые свойства, отличные от монометаллических НЧ, например, селективность в катализе, которые уже используются в синтезе биологически активных соединений [3]. Показано, что реакционная способность биметаллических НЧ определяется их структурой: интерметаллические соединения в виде сплава или состава «ядро-оболочка» $[4,5]$.

Нанокомпозитные материалы на основе металлических наночастиц и природных пигментов представляют большой интерес. В природе эти пигменты отображают собой особую группу химически гетерогенных и биосинтетически не связанных молекул, которые присутствуют практически во всех таксономических группах (от бактерий, растений до животных) и имеют общую особенность: их электронная структура содержит хромофор, с которым связаны характерные цвета этих соединений. В настоящее время природные пигменты, выделенные из растительного сырья, используются в качестве активных добавок: в пищевой промышленности, косметике, фармацевтике, медицине [6]. Применение природных пигментов по их использованию в фотонике и наноэлектронике обсуждается в работах [7]. Жимолость Lonicera caerulea является одним из хорошо изученных растений, содержащих ценные природные пигменты. Популярность жимолости обусловлена сверхранним сроком созревания ягод, которые в средней полосе России готовы к употреблению в середине июня за 7-10 дней до начала созревания земляники. Плоды жимолости накапливают биологически активные вещества, которые обладают противовоспалительной и антибактериальной активностью [8-10]. Редкая темно-синяя окраска плодов жимолости обусловлена накоплением антоцианов, имеющих интенсивные полосы поглощения в УФи видимой области спектра [11]. В некоторых сор- 
тах жимолости содержание антоцианов достигает 400-450 мг/100 г ягод [12]. Нанокомпозиты на основе НЧ металлов и жимолости были использованы в модельных солнечных элементах в качестве высокоэффективных нанокатализаторов для сбора световой энергии [13].

Настоящая работа посвящена изучению оптических свойств НЧ Au, НЧ Ag и биметаллических НЧ $\mathrm{Au} / \mathrm{Ag}$. Особое внимание было уделено изучению методом UV-VIS спектрометрии взаимодействия НЧ $\mathrm{Au}$ с природными пигментами из жимолости.

\section{ЭКСПЕРИМЕНТАЛЬНАЯ ЧАСТЬ}

Для синтеза наночастиц металлов использовали водорастворимую соль нитрата серебра $\left(\mathrm{AgNO}_{3}\right)$ и золотохлористоводородную кислоту $\left(\mathrm{HAuCl}_{4} \cdot 4 \mathrm{H}_{2} \mathrm{O}\right)$ компании Реахим; натрий бис(2этилгексил) сульфосукцинат $\left(\mathrm{C}_{20} \mathrm{H}_{37} \mathrm{O}_{7} \mathrm{SNa}\right)(\mathrm{AOT})$ фирмы AcrosOrganics; кверцетин $\left(\mathrm{C}_{15} \mathrm{H}_{10} \mathrm{O}_{7} \cdot 2 \mathrm{H}_{2} \mathrm{O}\right)$ компании Merk; изооктан компании «КомпонентРеактив». Использованная вода проходила очистку с помощью лабораторной системы очистки воды Sartorius Stedim arium 611 и имела электропроводность 17.9 мкСм/см.

Спиртовой экстракт жимолости получен в соотношении: 1 часть свежих ягод и 1 часть спирта (по объему). Спиртовые растворы экстрактов из ягод были отфильтрованы. С целью определения степени агрегации молекул пигментов в исходных спиртовых экстрактах предварительно было проведено исследование влияния коэффициента разбавления экстрактов и времени хранения на спектры поглощения спиртовых разбавленных экстрактов.

Обратно-мицеллярный раствор (ОМР) ионов металлов готовили путем введения необходимого количества соответствующих водных растворов $\mathrm{HAuCl}_{4}$ и $\mathrm{AgNO}_{3}$ в раствор, содержащий 200 мкМ кверцетина в $0.15 \mathrm{M}$ растворе АОТ в изооктане. Содержание введённых солей в ОМР из растворов $0.048 \mathrm{M} \mathrm{HAuCl}_{4}$ и $0.3 \mathrm{M} \mathrm{AgNO}_{3}$ варьировалось в зависимости от выбранного значения степени гидратации, $\left(\omega=\left[\mathrm{H}_{2} \mathrm{O}\right] /[\mathrm{AOT}]\right)$. Синтез НЧ и хранение полученных НЧ металлов проходило при температуре $18-21^{\circ} \mathrm{C}$.

Исследование кинетики формирования НЧ позволило установить, что основной процесс формирования наноструктур заканчивается за 10 - 15 суток [14]. Данные по размерам и дифракционные изображения наночастиц представлены в работе [14], размеры НЧ Ag $\omega=5.0$ от 6 до $12 \mathrm{Hм;} \mathrm{НЧ} \mathrm{Au}$ $\omega=5.0$ от 1.5 до 20 нм; НЧ $\mathrm{Au}-\mathrm{Ag} \omega=5.0$ размер отдельных частиц 10-15 нм.
Спектры оптического поглощения (ОП) и люминесценции (Lum) измерялись в области от 190 до 900 нм при использовании спектрофотометра Hitachi U-3310 и флюориметра Hitachi F-7000; длина оптического пути кварцевых кювет 1.0 и 10.0 мм соответственно. Раствором сравнения был растворитель: этанол или АОТ/изооктан.

\section{РЕЗУЛЬТАТЫ И ИХ ОБСУЖДЕНИЕ}

В работе исследовали оптические свойства металлических НЧ Au, НЧ Ag и биметаллических НЧ $\mathrm{Au} / \mathrm{Ag}$, синтезированные на основе реакции химического (Chem) восстановления ионов металлов в обратных мицеллах в присутствии природного пигмента - кверцетина (Qr) и молекулярного кислорода [15]. Ранее было установлено, что в анаэробных условиях НЧ не образуются, то есть кислород не только не мешает «восстановлению» ионов металла, а его присутствие необходимо [16].

Формирование оксо-комплексов Qr с кислородом и участие лабильного тройного комплекса $\left[\mathrm{nQr}^{\delta+} \ldots \mathrm{mO}_{2}^{\delta-} \ldots \mathrm{pMe}^{+}\right]$в качестве прекурсора НЧ доказано в работе [18]. Кинетика образования промежуточных комплексов и формирования НЧ Ag была исследована в работе [19]. В этой работе при изучении влияния $\omega$ (соответственно и концентрации соли в водном пуле ОМ) на кинетику формирования НЧ Ag была зарегистрирована полоса поглощения тройного комплекса $\left[\mathrm{nQr}^{\delta^{+}} \ldots \mathrm{mO}_{2}^{\delta-} \ldots \mathrm{pAg}^{+}\right]$ для ОМР с наименьшим значением $\omega$, равным 1.0 (представлена на рис. $1 b$ ).

На рис. 1 а представлены результаты изменения оптической плотности различных ОМР НЧ $\mathrm{Au}$ Chem при значении $\omega=5.0$ в течение 1 месяца. Снижение интенсивности полосы поглощения Qr $(\lambda \sim 380$ нм) указывает на уменьшение концентрации Qr за счет участия в реакции восстановления ионов Au. Следует обратить внимание на изменение скорости снижения концентрации Qr и скорости формирования НЧ Ag и НЧ Au от времени в зависимости от значения выбранных коэффициентов солюбилизации $\omega_{i}$.

Поскольку обратно мицеллярные растворы являются прозрачными системами в широкой области спектра, исследование оптических характеристик спектров ОП и Lum металлических и биметаллических наночастиц позволило обнаружить их существенное различие. На рис. 2 представлены спектры ОП НЧ Аu $(\omega=5.0)$, биметаллических НЧ $\mathrm{Au} / \mathrm{Ag}(\omega=5.0$ и 10.0) и для сравнения НЧ Ag $(\omega=5.0)$ (кривая 4). Видно, что характер спектра ОП биметаллических НЧ $\mathrm{Au} / \mathrm{Ag}$ существенно от- 

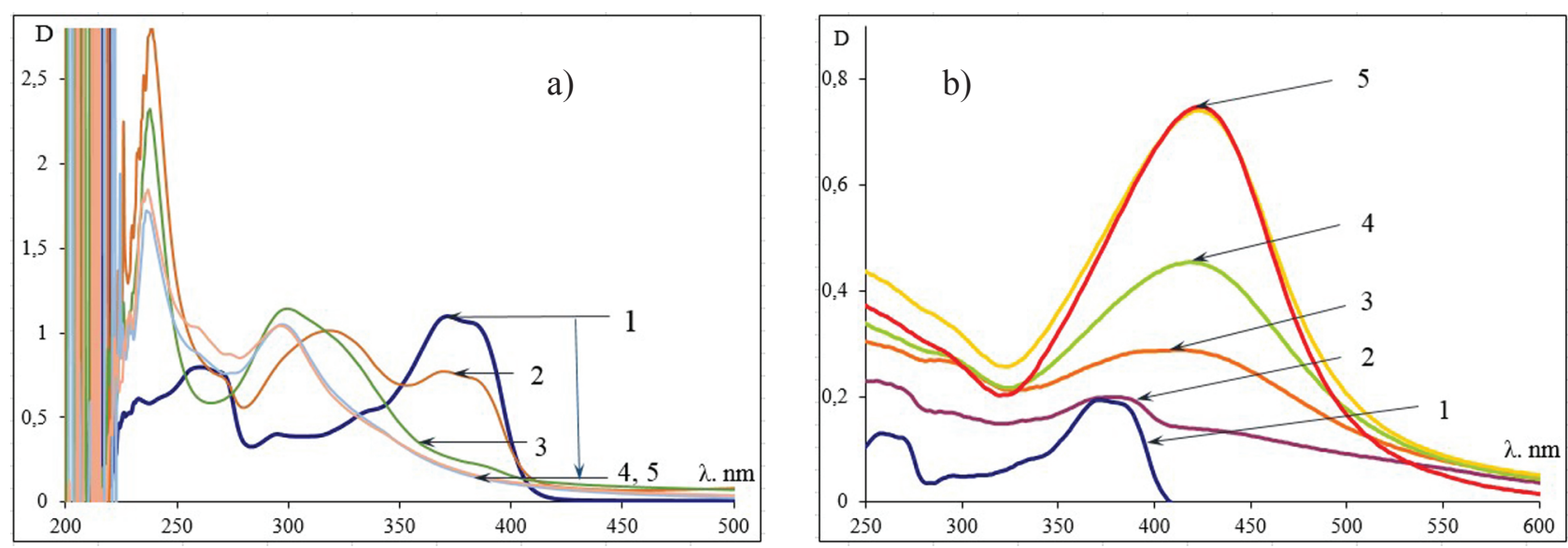

Рис. 1. Спектры ОП НЧ $\mathrm{Au} \omega=5.0-a, \mathrm{Ag} \omega=1.0-b$ и кверцетина -1 : сразу после введения водных растворов $\mathrm{HAuCl}_{4}$ и $\mathrm{AgNO}_{3}$ в раствор 200 мкM Qr/0.15 M AOT/изооктан - 2; $\Delta t=2$ ч - 3; 24 ч - 4; 1 месяц - 5

[Fig. 1. Spectra of absorbance of nanoparticles (NP's) Au $\omega=5.0-a, \mathrm{Ag} \omega=1.0-b$ and quercetin- 1: immediately after the introduction of aqueous solutions of salts $\mathrm{HAuCl}_{4}$ and $\mathrm{AgNO}_{3}$ in a solution of $200 \mu \mathrm{m} \mathrm{Qr} / 0.15 \mathrm{M} \mathrm{AOT/}$ isooctane- $2 ; \Delta t=2 \mathrm{~h}-3 ; 24 \mathrm{~h}-4 ; 1$ month -5$]$
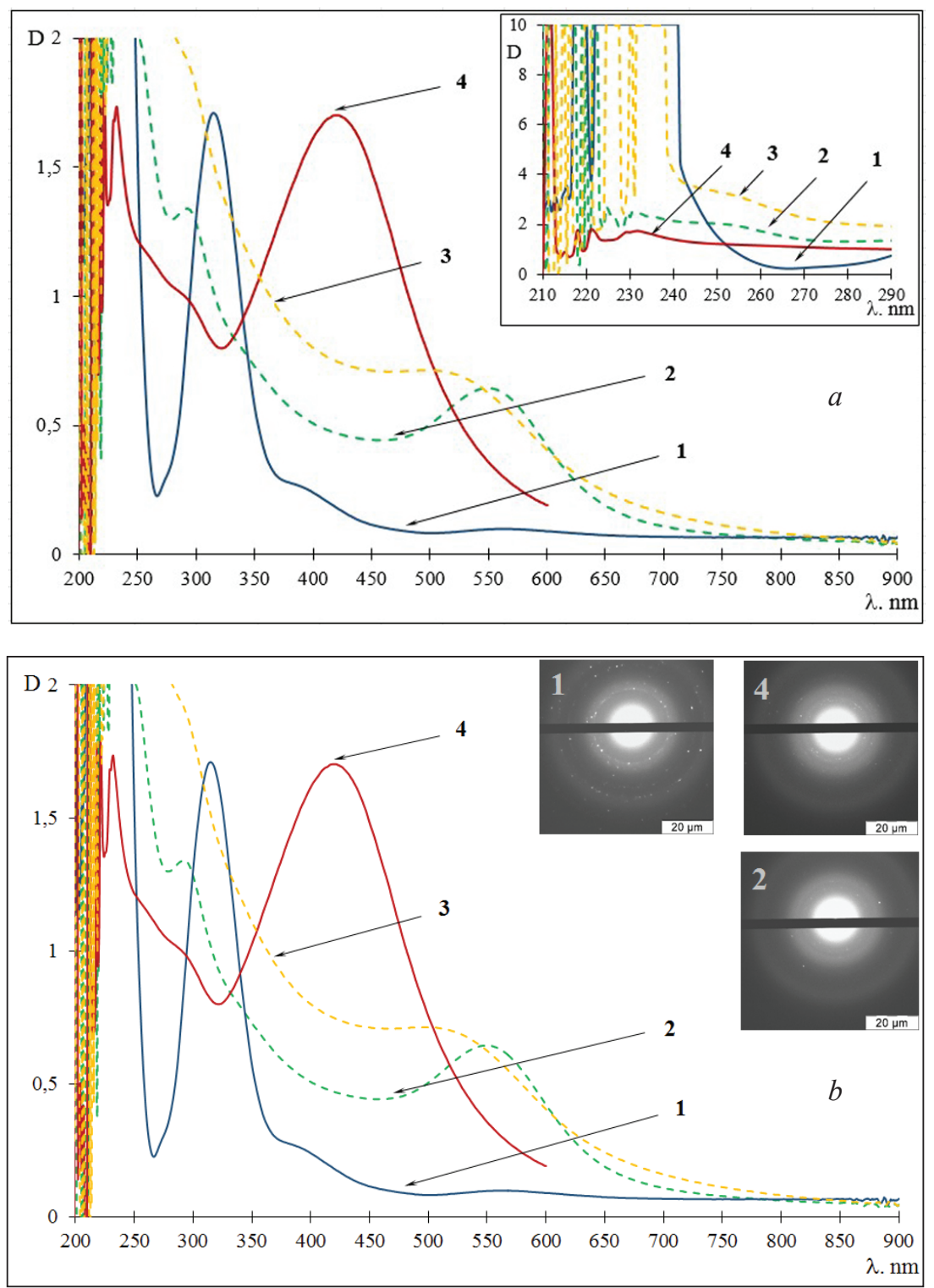

Рис. 2. Спектры оптического поглощения ОМР стабильных НЧ: Аu $(\omega=$ $5.0)$ - 1 ; HЧ Au/Ag $(\omega=5.0)$ - 2; HЧ $\mathrm{Au} / \mathrm{Ag}(\omega=10.0)-3 ; \mathrm{HЧ} \mathrm{Ag}(\omega=5.0)$ - 4. Вставка к рис. $2 a$ : Спектры оптического поглощения ОМР стабильных НЧ в области от 210 до 290 нм. Вставка к рис. $2 b$ : Электронная дифракционная картина НЧ $\mathrm{Au}(\omega=5.0)$ -1 ; НЧ Ag $(\omega=5.0)-4$; НЧ Au/Ag $(\omega$ $=5.0)-2$ [14]. Размеры соответствующих НЧ приведены в экспериментальной части этой статьи

[Fig. 2. Spectra of absorbance of reverse micellar solutions (RMS) of stable nanoparticles: $\mathrm{Au}(\omega=5.0)-1 ; \mathrm{Au} / \mathrm{Ag}$ $(\omega=5.0)-2 ; \mathrm{Au} / \mathrm{Ag}(\omega=10.0)-3 ; \mathrm{Ag}$ $(\omega=5.0)-4$. Insert to Fig. $2 a$ : Optical absorption spectra of RMS of stable NP's in the range from 210 to $290 \mathrm{~nm}$. Insert to Fig. $2 b$ : Electronic diffraction pattern AU $(\omega=5.0)-1$; Ag $(\omega=5.0)$ $-4 ; \mathrm{Au} / \mathrm{Ag}(\omega=5.0)-2$ [14]. The dimensions of the corresponding NP's are given in the experimental part of this article] 
личается от спектров моночастиц: по интенсивности и положению характерных полос поглощения. Следует обратить внимание, что интенсивность полосы, характерной для НЧ Аu в области 540 нм, составляет менее 0.1 , в то время как для биметаллических НЧ интенсивность полосы равна $\sim 0.65$ [20]. Важно отметить, что в спектрах поглощения $\mathrm{HЧ} \mathrm{Au} / \mathrm{Ag}$ не проявляется полоса поглощения $\mathrm{HЧ}$ $\operatorname{Ag} \lambda_{\max } \sim 420$ нм. Кроме того, можно отметить различие в интенсивностях полос поглощения биметаллических и НЧ Аu в области 200-240 нм (вставка к рис. 2).

Наблюдаемые различия в характеристиках спектров ОП моно- и биметаллических наночастиц были зарегистрированы при измерении спектров люминесценции (рис. 3). В спектрах люминесценции образца $0.15 \mathrm{M} \mathrm{AOT/изооктана} \mathrm{(объемом}$ 1.0 мл) (кривая 1) регистрируется увеличение интенсивности люминесценции (Ilum) при добавлении ОМР НЧ Аu ( $\omega=5.0)$ (кривые 2-5). Кроме того, в спектре Lum чистого OMP HЧ Au $(\omega=5.0)$ проявляется новая полоса в области $\lambda_{\max } \sim 340$ нм. На вставке (рис. 3) представлено изменение интенсивности люминесценции при $\lambda_{\max } \sim 308$ нм и $\lambda_{\max } \sim 325$ нм в зависимости от вводимого объема раствора НЧ Аu в 1.5 мл 0.15 М раствора АОТ в изооктане.

На рис. 4 изображено изменение спектров люминесценции раствора $0.15 \mathrm{M} \mathrm{AОТ/изооктана} \mathrm{(объ-}$ емом 1.0 мл) (кривая 1) за счет добавления ОМР НЧ Au/Ag ( $\omega=5.0)$ (кривые 2-6). Интенсивность люминесценции увеличивается при постепенном добавлении ОМР НЧ биметаллов. После введения более 150 мкл ОМР НЧ Au/Ag наблюдается снижение интенсивности люминесценции, что связано с «концентрационным эффектом». Интенсивность люминесценции (Ilum) чистого ОМР НЧ $\mathrm{Au} / \mathrm{Ag}(\omega=5.0)$ близка по значению с Ilum $0.15 \mathrm{M}$ АОТ/изооктан, но форма несколько отличается. На рис. 4 (вставка) показано изменение интенсивности люминесценции при $\lambda_{\max } \sim 308$ нм и $\lambda_{\max } \sim 325 \mathrm{Hм}$, $I_{\text {Lum }}=f(V$, мкл $)$ ОМР НЧ Au/Ag.
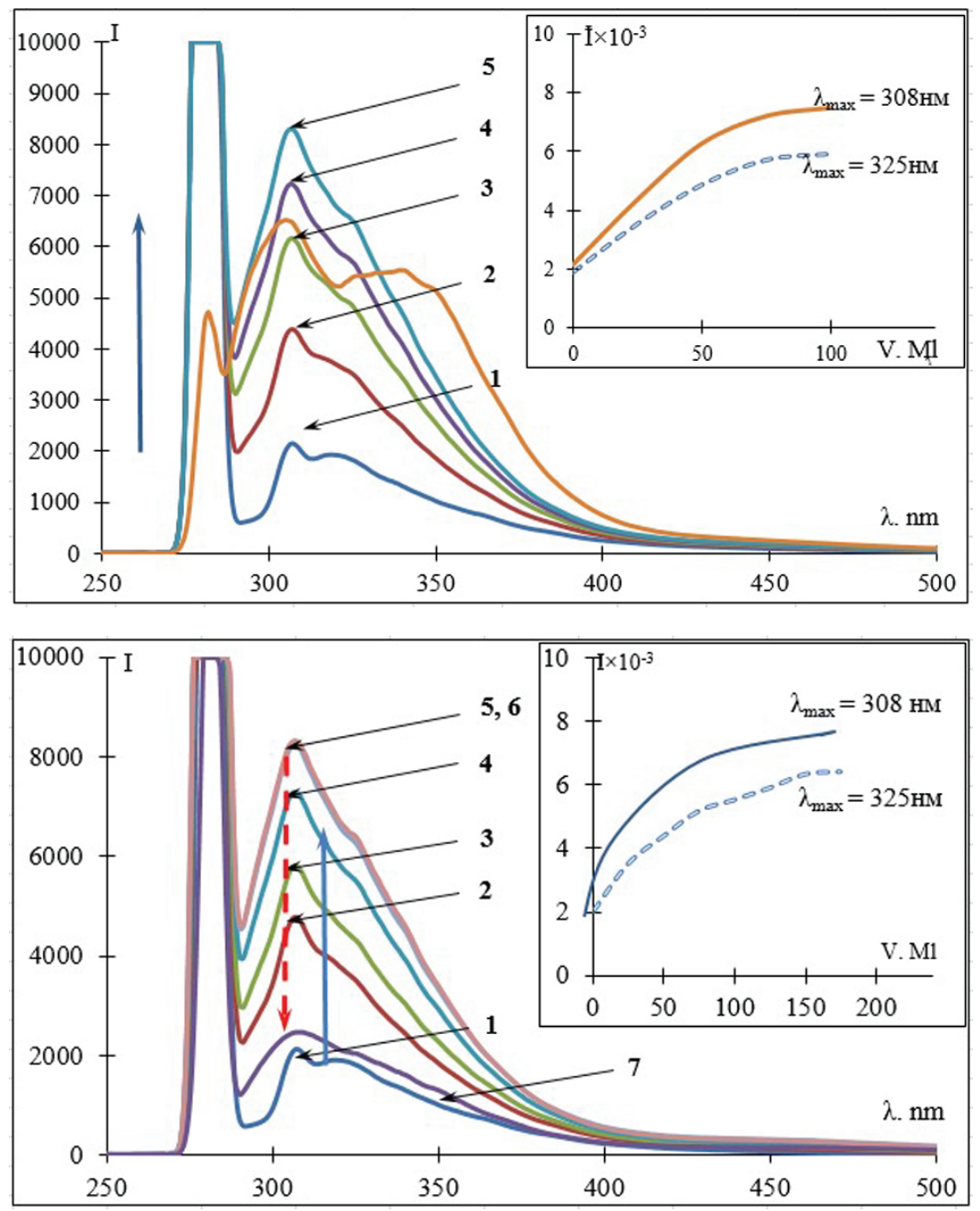

Рис. 3. Спектры люминесценции раствора $0.15 \mathrm{M} \mathrm{АОТ/изооктан} \mathrm{объ-}$ емом 1 мл (1) после добавления ОМР НЧ $\mathrm{Au}(\omega=5.0)$, мкл: $25-2 ; 50-3$; $100-4 ; 150-5$;

ОМР НЧ Аu (1 мл) $-6, \lambda_{\text {возб. }}=285 \mathrm{HM}$ [Fig. 3. Luminescence spectra of a solution $0.15 \mathrm{M}$ AOT/isooctan with a volume of $1 \mathrm{ml}(1)$, after addition of RMS of NP's Au ( $\omega=5.0), \mu 1$ : $25-2 ; 50-3$; $100-4 ; 150-5$; RMS of NP's Au $(1 \mathrm{ml})-6$, at $\left.\lambda_{\text {exc. }}=285 \mathrm{~nm}\right]$

Рис. 4. Люминесценция 0.15 М АОТ/ изооктан - 1; добавление 25 мкл НЧ $\mathrm{Au} / \mathrm{Ag}(\omega=5.0)$ в исходный АОТ/ изооктан - 2; 50 мкл - 3; 100 мкл - 4; 150 мкл - 5; 175 мкл- 6; 1 мл биметаллических НЧ $\mathrm{Au} / \mathrm{Ag}-7$

[Fig. 4. Luminescence of $0.15 \mathrm{M} \mathrm{AOT/}$ isooctane -1 ; add $25 \mu \mathrm{l} \mathrm{NP's} \mathrm{Au/Ag}$ $(\omega=5.0)$ in the initial AOT/isooctane $2 ; 50 \mu \mathrm{l}-3 ; 100 \mu \mathrm{l}-4 ; 150 \mu \mathrm{l}-5$; $175 \mu 1-6 ; 1 \mathrm{ml}$ bimetal NP's $\mathrm{Au} / \mathrm{Ag}-7]$ 


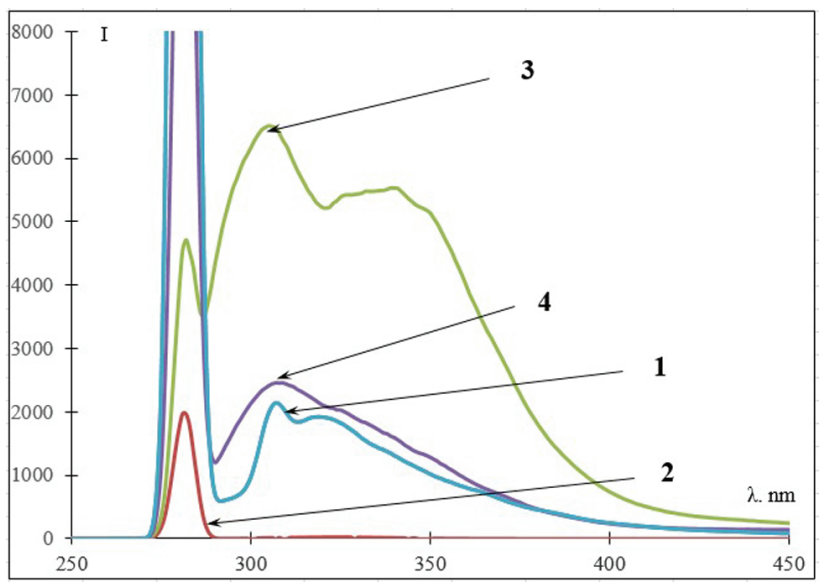

Рис. 5. Спектры люминесценции ОМР объемом 1 мл: $0.15 \mathrm{M} \mathrm{AОТ/изооктан} \mathrm{-} 1$; НЧ Ag $(\omega=5.0)-2$; НЧ Au $(\omega=5.0)-3 ; \mathrm{HЧ} \mathrm{Au} / \mathrm{Ag}(\omega=5.0)-4$

[Fig. 5. The luminescence spectra of RMS volume of $1 \mathrm{ml}$ : 0.15 M AOT/isooctane - 1; NP's Ag $(\omega=5.0)-2$; NP's Au $(\omega=5.0)-3$; NP's Au/Ag $(\omega=5.0)-4]$
Для сравнения люминесценции ОМР монометаллических и биметаллических наночастиц, представленных на рис. 5, показаны спектры люминесценции $0.15 \mathrm{M} \mathrm{АОТ/изооктан} \mathrm{и} \mathrm{НЧ} \mathrm{Au}(\omega=5.0)$, НЧ $\mathrm{Ag}(\omega=5.0)$ и НЧ $\mathrm{Au} / \mathrm{Ag}(\omega=5.0)$. Видно, что самым высоким значением люминесценции обладают образцы растворов НЧ $\mathrm{Au} \omega=5.0$ по сравнению с биметаллическими НЧ Au/Ag. В отличие от наночастиц золота наночастицы серебра полностью тушат люминесценцию 0.15 М АОТ/изооктан.

\section{Реакции взаимодействия НЧ Аu \\ с природными пигментами из экстрактов жимолости}

Для изучения взаимодействия НЧ Аu с природными пигментами были выбраны водно-спиртовые экстракты из жимолости, полоса основных пигментов которых и полоса поглощения ОМР НЧ Аu лежат в видимой области спектра с $\lambda_{\max } \sim 520-550$ нм. На рис. $6 a$ показаны изменения спектров ОП спиртового раствора жимолости после добавления НЧ Chem Au. Как можно видеть, интенсивность ОП
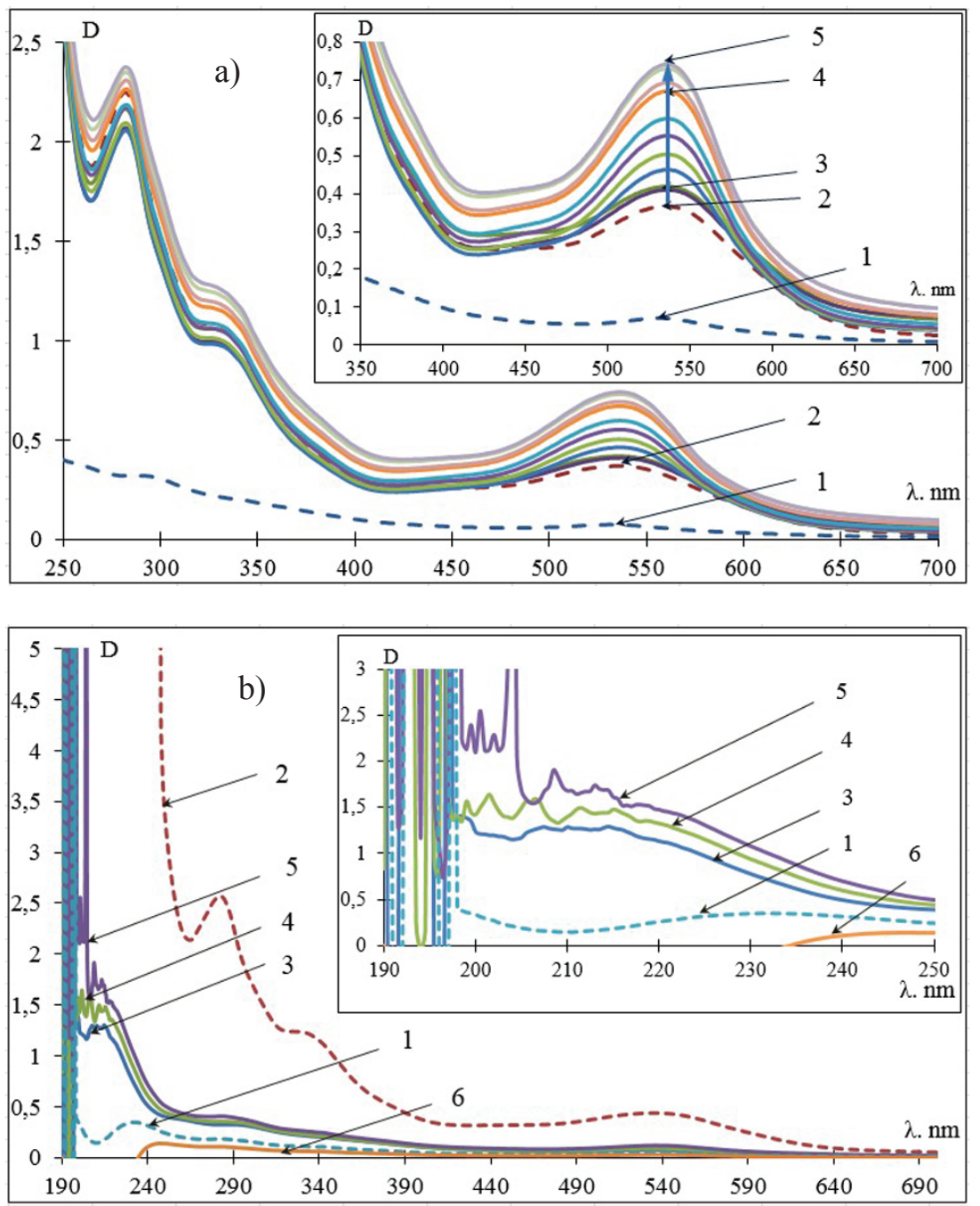

Рис. 6a. Спектры ОП: НЧ Au Chem ( $\omega$ $=5.0)-1$, спиртового экстракта жимолости - 2 (пунктирные линии). Увеличение интенсивности ОП раствора жимолости после постепенного добавления НЧ Au Chem $(\omega=5.0)$ от 25 мкл -3 , до соотношения $1: 1-4$ и до соотношения 2:1 - 5

Fig. 6a. Spectra of absorbance: NP's Au Chem $(\omega=5.0)-1$, alcoholic extract of honeysuckle -2 (dotted lines). Increase of intensity of OP of a solution of honeysuckle after gradual addition of NP's Au Chem $(\omega=5.0)$ from $25 \mu \mathrm{l}-3$, to a ratio $1: 1-4$ and to a ratio $2: 1-5$

Рис. 6b. Спектры ОП ОМР НЧ Аu Chem $(\omega=5.0)-1$ и последующее введение спиртового раствора экстракта жимолости - 2; 25 мкл жимолости $-3 ; 50$ мкл - 4; 75 мкл - 5; 100 мкл 6

Fig. 6b. Spectra of absorbance: NP's Au Chem $(\omega=5.0)-1$ and the subsequent introduction of alcoholic solution of the extract of honeysuckle $-2 ; 25 \mu$ l of honeysuckle $-3 ; 50 \mu \mathrm{l}-4 ; 75 \mu \mathrm{l}-5 ; 100 \mu \mathrm{l}$ $-6]$ 
значительно увеличивается при добавлении в раствор жимолости $\mathrm{HЧ} \mathrm{Au}$, которая достигает своего максимума при введении 2.0 мл раствора НЧ $\mathrm{Au}$, и после дальнейшего добавления жимолости ОП практически не изменяется, но отличается от интенсивности раствора жимолости рис. $6 a$, спектр 2.

Совершенно другой процесс взаимодействия происходит при внесении раствора жимолости в ОМР НЧ Au Chem $(\omega=5.0)$. На рис. $6 b$ показано, что введение малых порций ( 20-25 мкл) раствора жимолости почти не изменяет интенсивность полосы при $\lambda_{\max } \sim 540$ нм, но значительно, особенно при введении 75 мкл, увеличивается ОП в УФ области спектра. Однако добавление 100 мкл жимолости в раствор НЧ Аu приводит к деструкции раствора рис. $6 b$, кривая 6 .

\section{Жимолость и НЧ Au RadChem}

Для сравнения кроме химического способа восстановления наночастиц ионов металлов в жидкой фазе использовался радиационно-химический
(RadChem) способ. Основное отличие двух методов состоит в том, что при радиационно-химическом синтезе реакция восстановления проходит только в анаэробных условиях под действием $\gamma$-излучения, в то время как при химическом синтезе восстановление протекает только в присутствие молекулярного кислорода и восстановителя - кверцетина.

При изучении взаимодействия жимолости с $\mathrm{HЧ} \mathrm{Au,} \mathrm{полученных} \mathrm{двумя} \mathrm{методами} \mathrm{(RadChem} \mathrm{и}$ Chem), обнаружено, что метод восстановления ионов золота влияет на физико-химические свойства наночастиц, что отражается в механизме их взаимодействия с молекулами пигментов, как представлено на рис. $7 a$. Показаны изменения спектров оптического поглощения водно-спиртового раствора жимолости (кривая 2) после добавления ОМР НЧ Аи (кривые 3-6), полученных путем радиационно-химического восстановления ионов золота. Как видно, исходный раствор жимолости имеет интенсивную полосу поглощения (кривая 2), а при введении только 100 мкл раствора НЧ Аи ин-
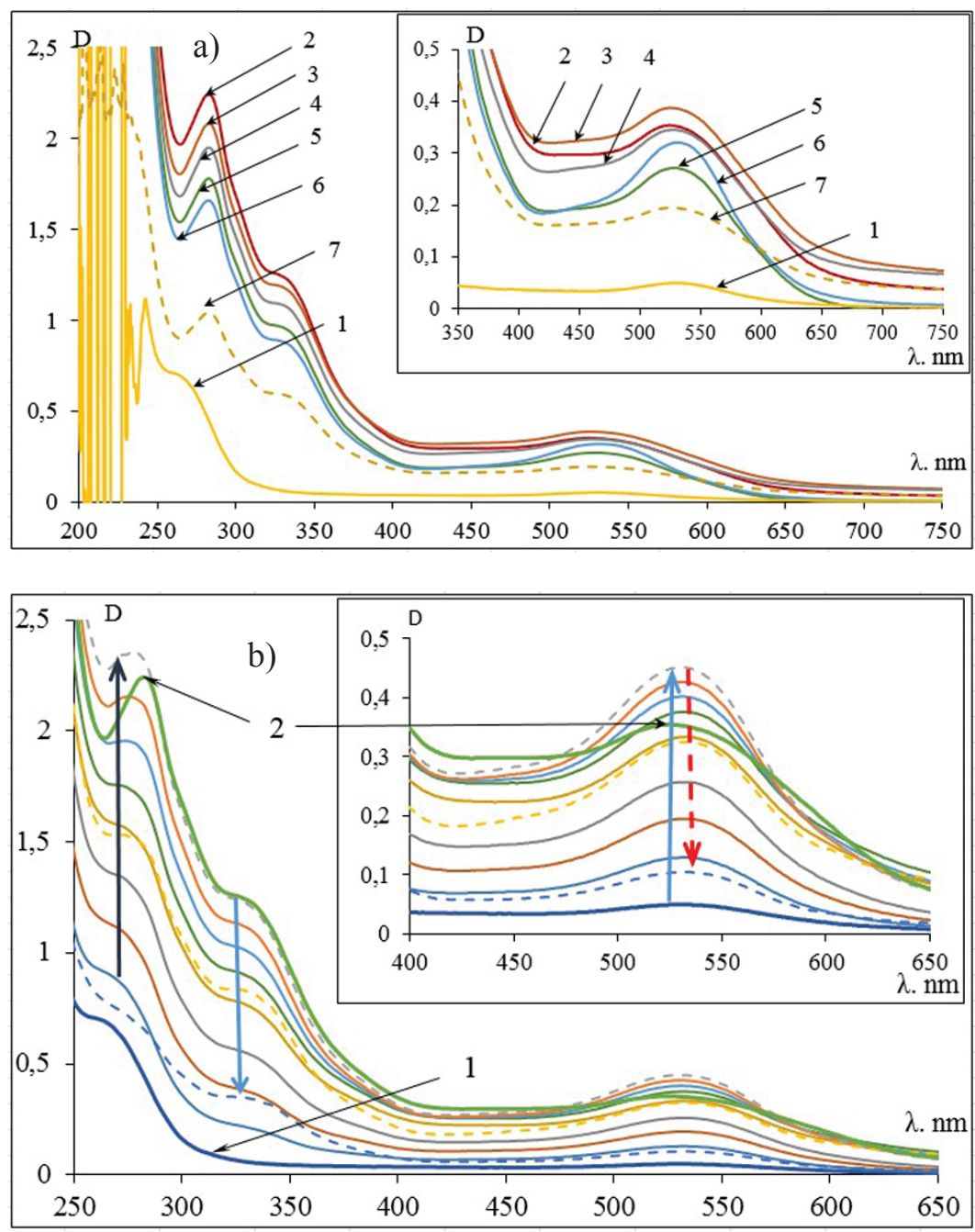

Рис. 7а. Изменение спектров ОП спиртового раствора жимолости (1.5 мл) - 2 при введении ОМР НЧАu RadChem $(\omega=5.0)-$ $1 ; 100$ мкл НЧ - 3; 200 мкл - 4; 500 мкл $5 ; 1.5$ мл (1:1) - 6; теоретическая кривая - 7. На вставке кинетика изменения спектров ОП в области $350-750$ нм

Fig. 7a. Change of spectra of absorbance of alcoholic solution of honeysuckle $(1.5 \mathrm{ml})$ 2 at introduction of RMS of NP's Au RadChem $(\omega=5.0)-1 ; 100 \mu 1$ of NP's -3 ; $200 \mu \mathrm{l}-4 ; 500 \mu \mathrm{l}-5 ; 1.5 \mathrm{ml}(1: 1)-6$; theoretical curve - 7. At the insertion of the kinetics of changes in absorbance spectra in the region of 350-750 $\mathrm{nm}$

Рис. 7b. Спектр ОП ОМР НЧ Аu RadChem $(\omega=5.0)-1$; рост ОП при добавлении спиртового раствора жимолости с шагом (25-50 мкл) - 2 от 25 мкл до 200 мкл сплошные линии, а дальнейшее добавление до 300 мкл снижение ОП - пунктирные линии. На вставке - изменение интенсивности полосы в области $400-650$ нм Fig. 7 b. Spectra of absorbance RMS NP's Au RadChem $(\omega=5.0)-1$; growth OP when you add alcohol solution of honeysuckle increments $(25-50 \mu \mathrm{l})-2 \mu \mathrm{l}$ from $25 \mu \mathrm{l}$ to 200 - solid line, and further addition of $300 \mu \mathrm{l}$ of the reducing optical density - dotted line. On the insert - change the intensity of the band in the area of 400-650 nm] 
тенсивность полосы при $\lambda_{\text {max }} \sim 540$ нм значительно увеличивается. Следует обратить внимание, что при большем количестве добавленных НЧ Аu (при соотношении НЧ $\mathrm{Au}$ и жимолости 1:1) происходит снижение интенсивности полос поглощения в УФ-области при $\lambda_{\max } \sim 270$ нм и $\lambda_{\max } \sim 340$ нм этого раствора и увеличение интенсивности полосы $\lambda_{\max } \sim 540$ нм с некоторым изменением формы. Более сложная картина трансформации этой полосы c $\lambda_{\max } \sim 540$ нм при одновременном уменьшении интенсивности поглощения в области $\lambda=650-700 \mathrm{Hм}$ (вставка к рис. $7 a$ ). Вероятно, такое изменение формы полосы связано с увеличением содержания НЧ $\mathrm{Au}\left(\lambda_{\max } \sim 540\right.$ нм) за счет разрушения более крупных частиц. Спектр ОП, отвечающий сумме спектров НЧ Аu (0.75 мл) и жимолости (0.75 мл), представлен на рис. $7 a$ спектром 7.

Как видно, на рис. $7 b$ представлен другой характер изменения спектров ОП ОМР НЧ Аu при введении раствора жимолости. Наблюдается максимальное увеличение интенсивности поглощения при добавлении 200 мкл пигмента в 1.5 мл ОМР. При последующем увеличении количества пигмента в образце обнаружено расслоение раствора и зарегистрировано снижение ОП (вставка к рис. 7b).

Таким образом, даже порядок введения компонентов в раствор влияет на механизм реакции их взаимодействия и, соответственно, на структуру спектров, полученных нанокомпозитов.

\section{ЗАКЛЮЧЕНИЕ}

Синтезированы металлические $\mathrm{HЧ} \mathrm{Ag}$ и $\mathrm{HЧ}$ $\mathrm{Au}$, биметаллические НЧ $\mathrm{Au} / \mathrm{Ag}$ в обратно мицеллярных растворах на основе химического восстановления ионов в присутствии восстановителя кверцетина и кислорода «методом молекулярной сборки».

Методом UV-VIS спектрофотометрии на основании результатов анализа спектров ОП обнаружено существенное различие в процессах формирования монометаллических НЧ $\mathrm{Au}$ и $\mathrm{Ag}$ и биметаллических НЧ $\mathrm{Au}-\mathrm{Ag}$;

Изучена люминесценция металлических и биметаллических наночастиц, а также люминесценция жимолости.

В работе представлены результаты по созданию нанокомпозитных материалов на основе золотосодержащих наноразмерных частиц и природных пигментов, полученных из спиртового экстракта жимолости, которые могут быть использованы для научных исследований и применений в медицине, энергетике и других областях науки техники.

\section{СПИСОК ЛИТЕРАТУРЫ}

1. Sardar R., Funston A. M., Mulvaney P., Murray R. W. // Langmuir, 2009, vol. 25, pp. 13840-13851. DOI: https://doi.org/10.1021/la9019475

2. Kim F., Song J. H., Yang P. // J. Am. Chem. Soc., 2002, vol. 124, pp. 14316-14317. DOI: https:// doi.org/10.1021/ja028110o

3. Щенников С. В., Долуда В. Ю., Сульман Э. М., Сульман М. Г., Лакина Н. В., Бронштейн Л. М., Валецкий П. М. // Известия выстих учебных заведений. Химия и химическая технология, 2011, № 6, с. 61-63.

4. Kumari M. M, Jacob J., Philip D. // Spectroc. Acta Pt. A-Molec. Biomolec. Spectr., 2015, vol. 137, pp. 185-192. DOI: https://doi.org/10.1016/j. saa.2014.08.079

5. Lu L., Burkey G., Halaciuga I., Goia D. V. // J. Colloid Interface Sci., 2013, vol. 392, pp. 90-95. DOI: https://doi.org/10.1016/j.jcis.2012.09.057

6. Maran J. P., Priya B., Nivetha C. V. // Ind. Crop. Prod., 2015, vol. 63, pp. 182-189. DOI: https://doi. org/10.1016/j.indcrop.2014.09.059

7. Чернышова К. Ф., Ранабхат К., Тхан Тайк, Ревина А. А. Сборник материалов Международная конферениия со школой и мастер классами для молодых ученых. "Химическая технология функцииональных наноматериалов”. 30 ноября - 1 декабря, 2017, Москва, 2017, с. 287-288.

8. Ochmian I., Grajkowski J., Skupien K. // Bulletin UASVM Horticult., 2010, vol. 67, pp. 138-147. DOI: https://doi.org/10.1177/0146107910375548

9. Чепелева Г. Г., Тимошин А. В. // Химия растительного сырья, 2007, № 4, с. 125-126.

10. Skupien K., Ochmian I., Grajkowski J. // J. Fruit Ornament. Plant Res., 2009, vol. 17, pp. 101111.

11. Lila M. A. // J. Biomed. Biotechnol., 2004, vol. 5, pp. 306-313. DOI: https://doi.org/10.1155/ s111072430440401x

12. Гришанов А. Н., Жданов Е. А., Семкина Л. А., Мамаев С. А., Краснов В. А. // Химия $и$ технология растительных веществ: тез. Всерос. конф. Сывтывкар, 2000, с. 312

13. Ranabhat K., Skripkin K. S., Chernyshova K. F., Sofronova E. A., Revina A. A., Pylinina A. I., Patrikeev L. N., Lapshinsky V. A. // IOP Conference Series: Materials Science and Engineering (отправлена в печать в 2017 г.)

14. Чернышова К. Ф., Ревина А. А. // Наукоемкие технологии, 2017, т. 18, № 1, с. 45-50.

15. Ревина А. А. Патент РФ, № 2312741, 2007.

16. Ревина А. А. // Физикохимия поверхности и защитта материалов, 2009, т. 45, № 1, с. 58-63.

17. Докучаев А. Г., Мясоедов Т. Г., Ревина А. А. // ХВЭ, 1997, т. 31, № 5, с. 353-357.

18. Pileni M. P. // J. Phys. Chem. 1993, vol. 97, pp. 6961-6973. DOI: https://doi.org/10.1021/j100129a008 
19. Кузьмин В. И., Гадзаов А. Ф., Тытик Д. Л., Ревина А. А. и др. // Коллоидный журнал, 2014, т. 76, № 4, с. 477-485. D OI: $10.7868 /$ S0023291214030070
20. Дементьева О. В., Карцева М. Е., Огарев В. А., Сухов В. М., Рудой В. М. // Коллоидный журнал, 2016, т. 78, № 6, с. 713-721. DOI: 10.7868/ S0023291216060033

\title{
THE EFFECT OF NATURAL PIGMENT OF HONEYSUCKLE ON THE OPTICAL PROPERTIES OF Au NANOPARTICLES AND Au/Ag INVERSE MICELLAR SOLUTIONS
}

\author{
(C) 2018 K. F. Chernyshova, A. A. Revina \\ A. N. Frumkin Institute of Physical Chemistry and Electrochemistry of the RAS, \\ 31, Leninsky pr., Moscow 199071, Russia \\ e-mail:karish@list.ru
}

Received 27.03.2018

\begin{abstract}
Non-toxic, photo-and electro-catalytic active materials, based on metal nanoparticles synthesized in reverse micelles and natural pigments, have a number of advantages for the so-called "green" approach to the production of nanocomposites with the desired properties. This paper presents the results of the study of optical properties of nanoscale silver, gold, and bimetal gold-silver nanoparticles (NPs), obtained in inverse micellar solutions (RMS) by the reaction of chemical reduction (Chem) of $\mathrm{Me}^{\mathrm{n}+}$ ions induced by a reducing agent belonging to a class of flavonoids, i.e quercetin and molecular oxygen. Since inverse micellar solutions are transparent systems in a wide range of spectrum, the study of optical properties (optical density spectra and luminescence spectra) of metallic and bimetal nanoparticles allowed detecting the essential difference between them. The method of UV-VIS spectrophotometry was used to measure the formation kinetics of Au, Ag NPs, and bimetal $\mathrm{Au} / \mathrm{Ag} \mathrm{NPs}$, and their stability, depending on the storage time.

The composites based on metal nanoparticles and natural pigments are of particular interest to nanophotonics and nanoelectronics. The Lоnнсеra caerulŭa honeysuckle is one of the well-studied plants that contains valuable natural pigments. The fruit of honeysuckle is high in biologically active substances, organic acids, vitamins, tannins, and also contains coloured vegetable glycosides anthocyanins, responsible for the blue colour of the fruit.

This paper studies the influence of the natural pigment obtained from the water-alcohol extract of honeysuckle on the optical properties of inverse micellar solutions of Au NPs. Special attention was paid to the change in characteristics of the bands of optical absorption of RMS of Au NPs with the introduction into the solution of the alcoholic extract of honeysuckle natural pigments. More data regarding optical properties of RMS of Au NPs induced by honeysuckle was obtained by studying luminescence spectra of these solutions.

As a result, metal Ag NPs, Au NPs, and bimetal Au/Ag NPs, in inverse micellar solutions, based on the chemical reduction of ions induced by a reducing agent, i.e. quercetin and oxygen, were synthesized by the method of molecular assembly.

A significant difference in the formation kinetics of monometallic Au NPs, Ag NPs, and bimetallic $\mathrm{Au}-\mathrm{Ag}$ NPs was revealed.

The luminescence of metal and bimetallic nanoparticles and the luminescence of honeysuckle were studied.

The paper presents the results of the production of nanocomposite materials based on gold-containing nanoscale particles and natural pigments derived from the alcohol extract of honeysuckle, which can be used for research in medicine, energy production, and other sciences.
\end{abstract}

Keywords: nanoparticles of metals, bimetals, inverse micelles, spectra of optical absorption, luminescence spectra, degree of hydration, natural pigments.

DOI: https://doi.org/10.17308/kcmf.2018.20/521 


\section{REFERENCES}

1. Sardar R., Funston A. M., Mulvaney P., Murray R. W. Langmuir, 2009, vol. 25, pp. 13840-13851. DOI: https://doi. org/10.1021/la9019475

2. Kim F., Song J. H., Yang P. J. Am. Chem. Soc., 2002, vol. 124, pp. 14316-14317. DOI: https://doi.org/10.1021/ ja028110o

3. Shennikov S. V., Doluda V. U., Sulyman E. M., Sulyman M.G., Lakina N.V., Bronshteyn L. M., Valeckiy P. M. Chemistry and Chemical Technology, 2011, no. 6, pp. 61-63. (in Russ.)

4. Kumari M. M, Jacob J., Philip D. Spectroc. Acta Pt. A-Molec. Biomolec. Spectr., 2015, vol. 137, pp. 185-192. DOI: https://doi.org/10.1016/j.saa.2014.08.079

5. Lu L., Burkey G., Halaciuga I., Goia D. V. J. Colloid Interface Sci., 2013, vol. 392, pp. 90-95. DOI: https://doi. org/10.1016/j.jcis.2012.09.057

6. Maran J. P., Priya B., Nivetha C. V. Ind. Crop. Prod., 2015, vol. 63, pp. 182-189. DOI: https://doi. org/10.1016/j.indcrop.2014.09.059

7. Chernyshova K. F., Ranabhat K., Than Tayk, Revina A. A. Collection of Materials International Conference with School and Master Classes for Young Scientists. "Chemical Technology of Functional Nanomaterials", Proc. Conf., November 30 - December 1, 2017, Moscow, 2017, pp. 287288 (in Russ.)

8. Ochmian I., Grajkowski J., Skupien K. Bulletin UASVM Horticult., 2010, vol. 67, pp. 138-147. DOI: https:// doi.org/10.1177/0146107910375548

9. Chepeleva G. G., Timoshin A. V. Khimija Rastitel'nogo Syr 'ja [Chemistry of Vegetable Raw Materials], 2007, no. 4, pp. 125-126. (in Russ.)
10. Skupien K., Ochmian I., Grajkowski J. J. Fruit Ornament. Plant Res., 2009, vol. 17, pp. 101-111.

11. Lila M. A. J. Biomed. Biotechnol., 2004, vol. 5, pp. 306-313. DOI: https://doi.org/10.1155/s11107243 0440401x

12. Grishanov A. N., Zhdanov E. A., Semkina L. A., Mamaev S. A., Krasnov V. A. Chemistry and Technology of Plant Substances: Theses all-Russian Conf., Syktyvkar, 2000, pp. 312. (in Russ.)

13. Ranabhat K., Skripkin K. S., Chernyshova K. F., Sofronova E. A., Revina A. A., Pylinina A. I., Patrikeev L. N., Lapshinsky V. A. IOP Conference Series: Materials Science and Engineering (sent to print in 2017). (in Russ.)

14. Chernyshova K. F., Revina A. A. Naukoemkie tekhnologii [Science Intensive Technologies], 2017, vol. 18, no. 1, pp. 45-50. (in Russ.)

15. Revina A. A. Patent RF, no. 2312741, 2007. (in Russ.)

16. Revina A. A. Protection of Metals and Physical Chemistry of Surfaces, 2009, vol. 45, no. 1, pp. 54-59. DOI: 10.1134/S2070205109010080

17. Dokuchaev A. G., Myasoedov T. G., Revina A. A. High Energy Chemistry, 1997, vol. 31, no. 5, pp. 353-357 (in Russ.)

18. Pileni M. P. J. Phys. Chem. 1993. vol. 97, p. 69616973. DOI: https://doi.org/10.1021/j100129a008

19. Kuzymin V. I., Gadzaov A. F., Tytik D. L., Revina A. A. Colloid Journal, 2014, vol. 76, no. 4, pp. 439-446 DOI: 10.1134/S1061933X14030077

20. Dementyeva O. V., Karceva M. E., Ogarev V. A., Suhov V. M., Rudoy V. M. Colloidal journal, 2016, vol. 78, no. 6, pp. 713-721. DOI: 10.7868/S0023291216060033 (in Russ.)
Чернышова Карина Фаритовна - м. н. с., Институт физической химии и электрохимии им. А.Н.Фрумкина РАН; тел.: +7 (909) 9699422; e-mail: karish@list.ru

Ревина Александра Анатольевна - д.х.н., вед. н. с., профессор, Институт физической химии и электрохимии им. А.Н. Фрумкина РАН; тел.: +7 (903) 2615731; e-mail: alex_revina@mail.ru
Karina F. Chernyshova - Junior Researcher, A.N. Frumkin Institute of Physical Chemistry and Electrochemistry of the RAS; tel.: +7 (909) 9699422, e-mail: karish@list.ru

Aleksandra A. Revina - Dr. Sc. (Chem), Leading Research Scientist, A.N. Frumkin Institute of Physical Chemistry and Electrochemistry of the RAS; tel.: +7 (903)2615731, e-mail: alex_revina@mail.ru 